\title{
p-Toluenesulfonyl Azide
}

\section{João Victor Santiago}

Instituto de Química de São Carlos, Universidade de São Paulo, CEP 13560-970, São Carlos, SP, Brazil

jvss@usp.br

jvss.qpa@gmail.com

Published online: 11.08 .2015

DOI: 10.1055/s-0034-1381138; Art ID: st-2015-v0525-v

\section{Introduction}

p-Toluenesulfonyl azide ( $\mathrm{TsN}_{3}$, CAS: 941-55-9) can be prepared in good yield from the reaction of $p$-toluenesulfonyl chloride $(\mathrm{TsCl})$ and sodium azide $\left(\mathrm{NaN}_{3}\right)$ (Scheme 1). ${ }^{1}$ $\mathrm{TsN}_{3}$ is a colorless oil with a melting point of $21-22{ }^{\circ} \mathrm{C}$ and boiling point of $110-115^{\circ} \mathrm{C}$ at $0.001 \mathrm{mmHg}{ }^{2}$

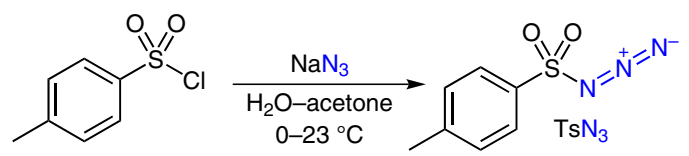

Scheme 1 Classic preparation of p-toluenesulfonyl azide
João Victor Santiago was born in 1991 in Brasília, Brazil. He obtained his B.Sc. in Chemistry (2012) and his M.Sc. in Organic Chemistry (2014) from the University of Brasília-UnB. Currently, he works towards his Ph.D. under the guidance of Professor Antonio C. B. Burtoloso. His research focuses on the synthesis of hexahydropyridazines, 1,2-oxazinanes, and substituted cyclohexanes from $\alpha, \beta$-unsaturated diazoketones.

One of the most used applications of $\mathrm{TsN}_{3}$ is the diazo transfer reaction. One of the first works to describe the conSince this date, the application of $\mathrm{TsN}_{3}$ in diazo chemistry is frequently mentioned. Other applications for $\mathrm{TsN}_{3}$ include cycloaddition reactions, especially the [3+2] cycloaddition with alkynes for the formation of substituted triazoles. ${ }^{4}$ Here, some recent examples of reactions employing $\mathrm{TsN}_{3}$ are presented.

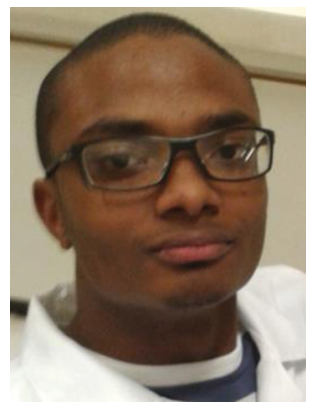
cept of diazo transfer was published in 1910 by Dimroth. ${ }^{3}$

Table 1 Use of $\mathrm{TsN}_{3}$
(A) Based on computational and mechanistic studies of copper-catalyzed azide-alkyne cycloaddition (CuAAC), Chang and co-workers ${ }^{5}$ have reported the regioselective synthesis of a series of $\mathrm{N}$-sulfonyl1,2,3-triazoles. CuI was employed as catalyst and 2,6-lutidine as an additive. $N$-Sulfonyl-1,2,3-triazoles were synthesized in 57-95\% yield.
(B) Zhang and co-workers ${ }^{6}$ reported the use of iron porpholactones as catalysts for the aziridination of alkenes and for the amidation of alkanes. In the aziridination of alkenes, mainly styrene derivatives were utilized as substrates. $\mathrm{TsN}_{3}$ acted as the nitrogen source. The authors synthesized a series of aziridines in $20-89 \%$ yield.

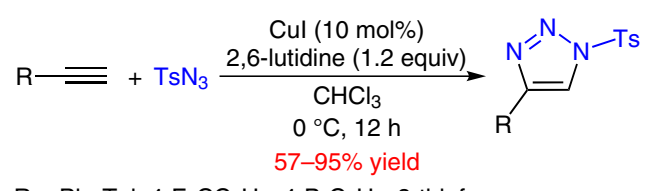

$\mathrm{R}=\mathrm{Ph}, \mathrm{Tol}, 4-\mathrm{F}_{3} \mathrm{CC}_{6} \mathrm{H}_{4}, 4-\mathrm{BrC}_{6} \mathrm{H}_{4}$, 3-thiofuran

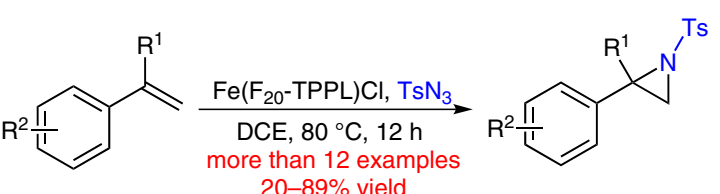

$\mathrm{R}^{1}=\mathrm{H}$ or $\mathrm{Me}$

$\mathrm{R}^{2}=4-\mathrm{Me}, 4-t-\mathrm{Bu}, 4-\mathrm{F}, 4-\mathrm{Cl}, 4-\mathrm{Br}, 4-\mathrm{OMe}$, $3-\mathrm{OMe}, \mathrm{Ph}$
(C) The application of $\alpha$-diazo- $N$-sulfonyl-imines as intermediates has often been reported. ${ }^{7}$ In 2013, Schultz and Sarpong ${ }^{8}$ performed the synthesis of 3,4-fused pyrroles using $\mathrm{TsN}_{3}$ in the formation of $\alpha$ $\mathrm{Rh}$-imino-carbenoid as an intermediate by the reaction of $\alpha$-diazo$\mathrm{N}$-tosyl-imines and a rhodium catalyst. In an one-pot methodology, the authors synthesized a series of 3,4-fused pyrroles in $47-92 \%$ yield.
1. $\mathrm{TsN}_{3}$, CuTc ( $\left.1 \mathrm{~mol} \%\right)$, r.t., $12 \mathrm{~h}$

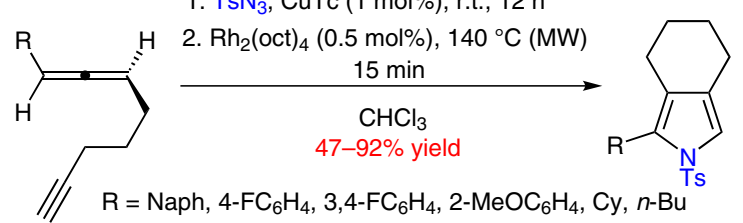


(D) Collins et al. ${ }^{9}$ reported the application of $\mathrm{TsN}_{3}$ as a reagent in the synthesis of $\alpha$-diazo- $\beta$-oxo-sulfoxides by a diazo-transfer reaction. In this work, the authors utilized sulfoxides containing monocyclic, bicyclic, or acyclic lactones and lactams. A series of $\alpha$-diazo- $\beta$-oxosulfoxides were synthesized in $10-62 \%$ yield.

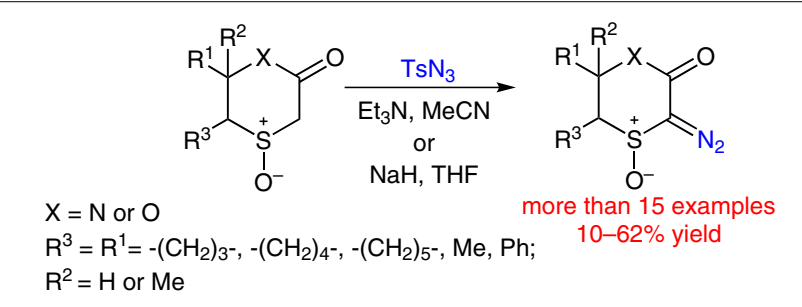

(E) Lee and $\mathrm{Xia}^{10}$ have reported the regioselective synthesis of a series of functionalized furans from the reaction of terminal alkynes and cyclic or acyclic diazocarbonyl compounds. The authors utilized $\mathrm{TsN}_{3}$ in a diazo-transfer reaction, furnishing diazocarbonyl compounds in $86-94 \%$ yield. ${ }^{11}$ The products were utilized in the synthesis of functionalized furans in $29-89 \%$ yield by a rutheniumcatalyzed [3+2] cycloaddition.

(F) $\mathrm{C}-\mathrm{H}$ bond activation is versatility and has been widely applied in organic synthesis for the formation of functionalized bonds. In 2014, Chang and $\mathrm{Kim}^{12}$ reported the iridium-catalyzed amidation of $\mathrm{C}-\mathrm{H}$ bonds in $\alpha$-aryl or $\alpha, \beta$-unsaturated carbonyl compounds (esters or ketones). The authors propose that $\mathrm{TsN}_{3}$ allows the formation of the $\mathrm{C}-\mathrm{N}$ bond by insertion of the amide group, followed by the extrusion of molecular nitrogen. In this work, more than 20 products of C-H insertion were synthesized in 51-99\% yield.

(G) Kanai and co-workers ${ }^{13}$ reported the directed selective amidation of $\mathrm{C}-2$ carbons on an indole nucleus by $\mathrm{C}-\mathrm{H}$ bond activation. The authors utilized an in situ generated cobalt catalyst for the transformation. $\mathrm{TsN}_{3}$ was employed as the reagent for the insertion of $\mathrm{N}$-tosyl into the C-2 carbon, furnishing the products in $85-92 \%$ yield.
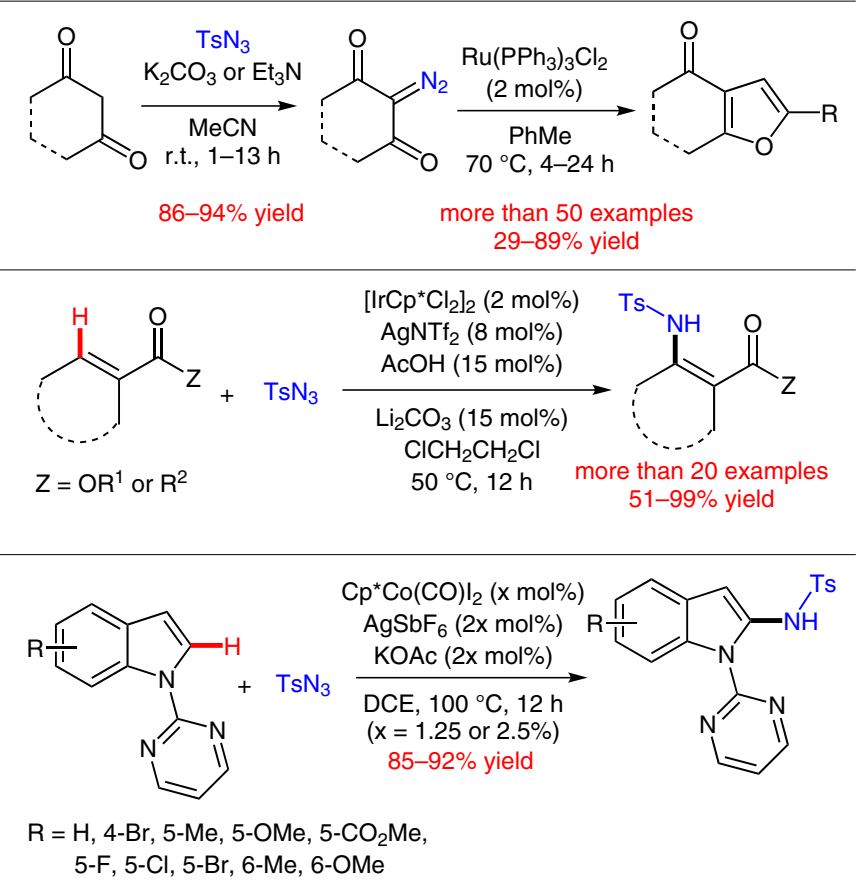

(H) Yavari and co-workers ${ }^{14}$ synthesized a series of pentasubstituted pyridines by copper catalysis using a tandem process. Sulfonyl compounds, including $\mathrm{TsN}_{3}$, were utilized for the formation of sulfonoketenimides as key intermediates, which in one step furnished pentasubstituted pyridines with good yields (69-85\%).

\section{References}

(1) Huisgen, R.; Möbius, L.; Müller, G.; Stangl, H.; Szeimies, G.; Vernon, J. M. Chem. Ber. 1965, 98, 3992.

(2) Heydt, H.; Regitz, M.; Mapp, A. K.; Chen, B. p-Toluenesulfonyl Azide, In e-EROS Encyclopedia of Reagents for Organic Synthesis; 2008.

(3) Dimroth, O. Ann. Chem. 1910, 373, 366.

(4) For examples, see: (a) Miura, T.; Yamauchi, M.; Murakami, M. Chem. Commun. 2009, 1470. (b) Zibinsky, M.; Fokin, V. V. Angew. Chem., Int. Ed. 2013, 52, 1507. (c) Horneff, T.; Chuprakov, S.; Chernyak, N.; Gevorgyan, V.; Fokin, V. V.J. Am. Chem. Soc. 2008, $130,14972$.

(5) Yoo, E. J.; Ahlquist, M.; Kim, S. H.; Bae, I.; Fokin, V. V.; Sharpless, K. B.; Chang, S. Angew. Chem. Int. Ed. 2007, 46, 1730.

(6) Liang, L.; Lv, H.; Yu, Y.; Wang, P.; Zhang, J.-L. Dalton Trans. 2012, $41,1457$.
(7) For examples, see: (a) Cassidy, M. P.; Raushel, J.; Fokin, V. V. Angew. Chem. Int. Ed. 2006, 45, 3154. (b) Horneff, T.; Chuprakov, S.; Chernyak, N.; Gevorgyan, V.; Fokin, V. V. J. Am. Chem. Soc. 2008, 130, 14972. (c) Zibinsky, M.; Fokin, V. V. Angew. Chem. Int. Ed. 2013, 52, 1507.

(8) Schultz, E. E.; Sarpong, R. J. Am. Chem. Soc. 2013, 135, 4696.

(9) Collins, S. G.; O'Sullivan, O. C. M.; Kelleher, P. G.; Maguire, A. R. Org. Biomol. Chem. 2013, 11, 1706.

(10) Xia, L.; Lee, Y. R. Eur.J. Org. Chem. 2014, 3430.

(11) Presset, M.; Mailhol, D.; Coquerel, Y.; Rodriguez, J. Synthesis 2011, 2549.

(12) Kim, J.; Chang, S. Angew. Chem. Int. Ed. 2014, 53, 2203.

(13) Sun, B.; Yoshino, T.; Matsunaga, S.; Kanai, M. Adv. Synth. Catal. 2014, 356, 1491.

(14) Yavari, I.; Taheri, Z.; Nematpour, M.; Sheikhi, A. Synlett 2014, 25, 2036. 